\title{
Commentary: Dressing for success
}

\author{
Randall Wolf, MD
}

Throughout the history of surgical innovation, surgeons have performed a new procedure or tried a new device or medication in moribund patients. Accordingly, our initial surgical results with new techniques are often less than stellar. The first 9 patients who underwent mitral valve replacement all died.

For the current article $^{1}$ on assessments of venous grafts treated with a novel solution to prevent vein graft disease, the authors have thought carefully about all the pitfalls of coronary grafting with venous conduits and have presented a novel treatment for vein grafts: not only impressive for the results of the treated grafts but also for the excellent patency of the placebo arm of the trial.

Fifteen years ago, in 2005, the PREVENT IV efficacy and safety results were published in $J A M A .^{2}$ Edifoligide, an E2F transcription factor decoy, was used to prevent vein graft failure following coronary artery bypass graft surgery. The results were disappointing, not only because there appeared to be little advantage in treating grafts with the solution, but perhaps more concerning and depressing was the finding that out of the more than 2400 patients enrolled in the 12-month angiography cohort, vein graft occlusion was about $42 \%$ per patient!

The authors of the current study, assessing a different solution to prevent vein graft failure, have dressed for success. They have controlled (as much as possible) for poor run-off, small distal targets, sequential grafts, etc. Thankfully, for the first time since PREVENT IV, we not only witness a favorable effect from the vein graft treatment, we can also report to our patients that vein graft failure in the cohort of patients in this study is low- $7 \%$ to $9 \%$. Given the fact that the most patients undergoing surgical revascularization for multivessel

\footnotetext{
From the DeBakey Heart and Vascular Center, Houston Methodist Hospital, Texas Medical Center, Houston, Tex.

Disclosures: Author has nothing to disclose with regard to commercial support.

Received for publication Oct 29, 2019; revisions received Oct 29, 2019; accepted for publication Oct 29, 2019; available ahead of print Nov 27, 2019.

Address for reprints: Randall Wolf, MD, DeBakey Heart and Vascular Center, Houston Methodist Hospital, Texas Medical Center, 6550 Fannin St, Suite 1401, Houston, TX 77006 (E-mail: randallwolfmd@mac.com or rkwolf@houstonmethodist. org).

J Thorac Cardiovasc Surg 2021;161:109

$0022-5223 / \$ 36.00$

Copyright (c) 2019 by The American Association for Thoracic Surgery

https://doi.org/10.1016/j.jtcvs.2019.10.197
}

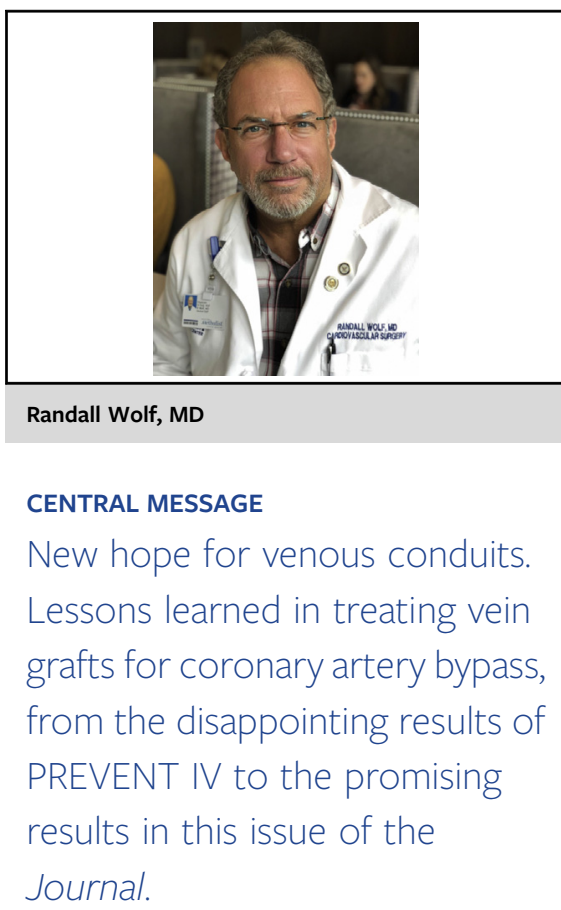

obstructive coronary artery disease have more vein grafts than arterial grafts, it is of great interest to the readers of the Journal.

Finally, we have some good news. The authors of this paper, and the surgeons who selected and performed the procedures, are to be congratulated for a job well done. Perhaps there is another message here. Namely, if cardiac surgeons choose wisely which targets to revascularize, the patency results for both arterial and venous conduits is excellent. It has been dogma to some of us that we should limit the number of grafts in coronary revascularization, and for most situations of multivessel revascularization, 3 grafts are enough. Indirectly, the current study supports this dogma. We should dress for success. Something we might consider more often. Hopefully, long-term patency will improve with this novel treatment as well. Time will tell.

\section{References}

1. Perrault P, Carrier M, Voisine P, Olsen PS, Noiseux N, Jeanmart H, et al Sequential multidetector computed tomography assessments after venous graft treatment solution in coronary artery bypass grafting. J Thorac Cardiovasc Surg. 2021;161:96-106.e2.

2. Alexander JH, Hafley G, Harrington RA, Peterson ED, Ferguson TB Jr, Lorenz TJ et al. Efficacy and safety of edifoligide, an E2F transcription factor decoy, for prevention of vein graft failure following coronary artery bypass graft surgery: PREVENT IV: a randomized controlled trial. JAMA. 2005;294:2446-54. 